\title{
EFFECTS FROM LOG-YARD STORMWATER RUNOFF ON THE MICROALGAE Scenedesmus subspicatus
}

\author{
Fabio Kaczala $^{a, b}$ \\ Paulo S. Salomon ${ }^{c}$, \\ Marcia Marques ${ }^{a, d}$, \\ Edna Granéli ', \\ William Hogland ${ }^{a}$ \\ ${ }^{a}$ School of Natural Sciences, Linnaeus University, Landgången 3 - Kalmar 391 \\ 82, Sweden \\ ${ }^{b}$ The CAPES Foundation, Brazil Ministry of Education \\ ${ }^{c}$ Marine Sciences Centre, Linnaeus University, Landgången 3 - Kalmar 391 82, \\ Sweden \\ ${ }^{d}$ Department of Sanitary and Environmental Engineering, Rio de Janeiro State \\ University UERJ, São Francisco Xavier, 524, CEP 20551-030, Rio de Janeiro,
}

Brazil.

\begin{abstract}
The effects posed by stormwater runoff from an industrial log-yard on the microalgae Scenedesmus subspicatus have been investigated. The effects of stormwater runoff sampled during two rain events on the microalgae were determined in different concentrations (\% v:v). The test organisms were exposed to the stormwater runoff $96 \mathrm{~h}$ and the percentage change in growth rates in relation to a control culture were measured at exposure times of $24 \mathrm{~h}, 48 \mathrm{~h}, 72$ and $96 \mathrm{~h}$. Whereas the runoff from the first rain event posed in most cases growth stimulatory effects, the runoff from the second rain event inhibited algae growth. Differences in runoff physico-chemical characteristics combined with the hydrological factors of each rain event explained these opposite effects. The occurrence of the "first flush" phenomenon was studied and the results confirmed such occurrences in the second rain event. On the basis of normalized inhibitory effects and runoff volume, it was found that 42,51 and $50 \%$ of the inhibitory effects during exposures of 24,48 and $72 \mathrm{~h}$ were associated with the initial $4 \%$ of the total discharged volume. To conclude it can be stated that since the stormwater runoff of only 2 rain events posed negative effects on the test organisms, the potential environmental threats posed by these waters during the entire hydrological year needs to be better understood in order to propose an adequate management program.
\end{abstract}

\section{KEYWORDS}

Toxicity, first flush, wood-industry, stormwater, growth inhibition 


\section{INTRODUCTION}

It is widely known that non-point source pollution from urban stormwater runoff discharges a significant number of xenobiotics to water recipients [1], affecting aquatic organisms and deteriorating the ecosystem [2,3]. Although knowledge of stormwater runoff and pollutants transport from urban areas increase, little is known about stormwater runoff generated at industrial sites and their respective environmental impacts.

Among a number of industrial activities that might pose harmful effects to aquatic ecosystems, industrial areas that handle and store wood materials such as log-yards, sawmills and other wood-based by-products, raise concerns due to potential release of organic and inorganic compounds. According to [4], toxic effects on fishes and invertebrates are related to naturally occurring wood-related compounds such as aldehydes, phenols, terpenes and others. Furthermore, tannins, lignin; tropolones, resin acids and toxic metals such as zinc, aluminium and copper are of greatest concern due to their contribution to log-yards runoff toxicity $[5,6,7]$.

Physico-chemical characteristics of stormwater runoff from log-yards are related to (i) the species of trees stored; (ii) the proportion of runoff that comes in contact with stored wood; (iii) log-yard size; (iv) the period the logs are stored; (v) the ratio between logs surface area to log-yard area, etc. Consequently, stormwater runoff from log-yards might have different characteristics and pose varied environmental effects as well.

The intra-storm variability of toxic effects posed by rainfall-runoff of highway areas has been previously described [8]. Those authors observed that higher toxic effects on the early stages of the runoff were gradually reduced, and that $90 \%$ of toxic effects were associated with the first $20 \%$ of the total runoff volume. Even though the toxic effects posed by wood-related compounds have been demonstrated $[9,10,11,6,4]$, little is know concerning the intra-storm magnitude, variability and possible existence of toxic first flushes from stormwater runoff generated in log-yards.

The aim of this paper was to evaluate the magnitude and the intra-storm variability of the toxic effects posed by stormwater runoff originated from a log-yard during single storm events. Most studies previously carried out throughout entire hydrographs have focused on specific contaminant loads and less attention has been given to toxicity evaluation. Despite the useful information on levels of contamination provided, the effects on the biota are not obtained. It is essential to better understand the dynamics of adverse effects of these types of water and their magnitudes, to provide a basis for an appropriate proposal, design and implementation of stormwater runoff management strategies. For the purpose of this study the freshwater, unicellular microalga Scenedesmus subspicatus was selected as the test organism. Microalgae are considered ideal organisms for toxicological studies once they are primary producers and any adverse effects towards them, might influence higher levels of the food chain. Besides, microalgae have a short life cycle and are able to quickly respond to the environmental changes over a number of generations [12].

\section{MATERIALS AND METHODS}

\subsection{Industrial site}

The physico-chemical characterization of the stormwater runoff was carried out at the industrial log-yard located in Nybro, southeast of Sweden. The investigated drainage basin 
had a total area of approximately $117,000 \mathrm{~m}^{2}$ (Figure 1) and among different wood species stored in the area, oak (Quercus sp.) accounts for 40-50\% [13].

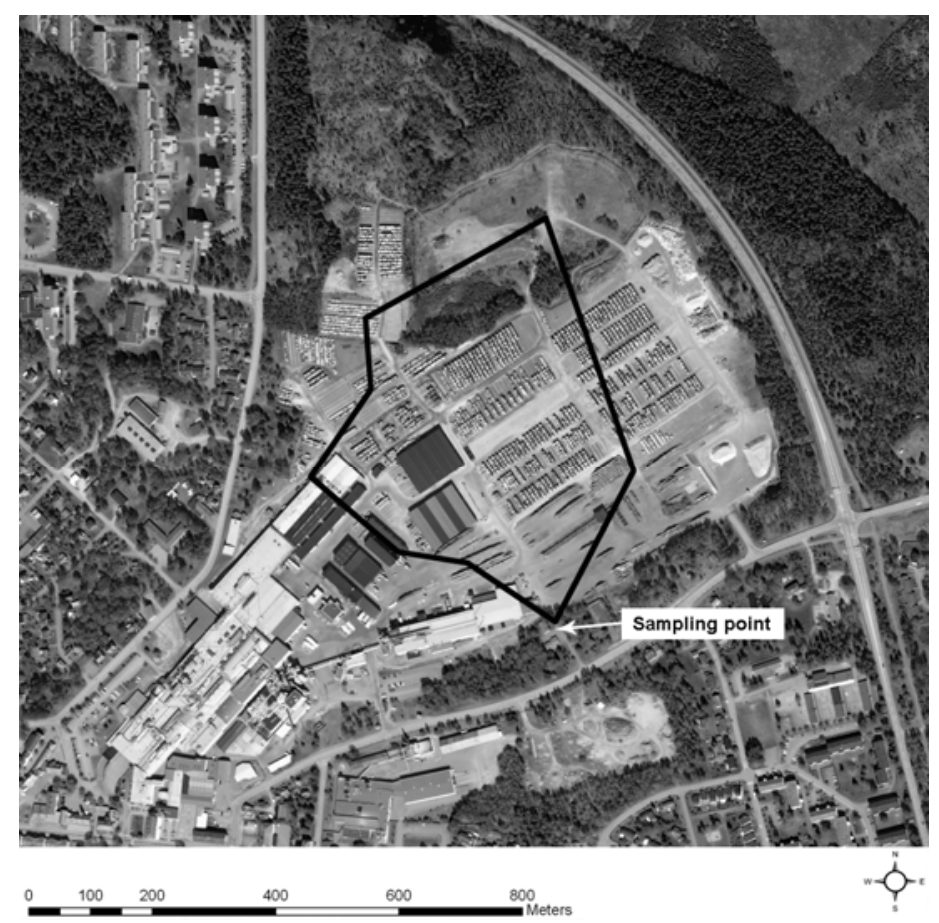

Figure 1: Aerial view of the log-yard drainage basin with the drainage boundaries. Scale $1: 5000[14]$

\subsection{Stormwater sampling and characterization}

Stormwater runoff generated by two single rain events during the summer of 2009 (June/July) were studied: (a) Rain 1, on June 18 and; (b) Rain 2, on July 1. The stormwater sampling and characterization procedures have been described by [14].

\subsection{Rainfall and flow measurement}

On-site precipitation was digitally recorded by an external "tipping bucket" rain gauge (SIGMA Model 2149). The standard area-velocity and Doppler principle method of flow measurement was used by a velocity submerged sensor (SIGMA Area velocity submerged sensor).

\subsection{Test organisms and experimental procedures}

The freshwater unicellular green alga Scenedesmus subspicatus was selected in this investigation. The stock culture was purchased from the algal culture collection at the University of Göttingen, Germany (SAG). The detailed description concerning the test organisms, cultivation procedures and the experimental set-up has been previously described elsewhere [14]

\subsection{Data analysis}


The effects of different concentrations of stormwater runoff were determined by comparing growth rates of exposed to non-exposed (negative controls) $S$. subspicatus in different exposure periods $(24,48,72$ and $96 \mathrm{~h})$. The average specific growth rate for $S$. subspicatus was given by:

$\mu=\frac{\left(\ln F_{t}\right)-\left(\ln F_{0}\right)}{\Delta t}$

where $\mu$ is the growth rate $\left(\mathrm{d}^{-1}\right), F_{t}$ and $F_{0}$ are the biomass measured as in vivo fluorescence (RFU) at time $t$ and $t_{0}$ respectively, and $\Delta t$ is the total exposure period $\left(t-t_{0}\right)$ in days.

On the basis of calculated growth rates, the $\%$ inhibitions were obtained as follows:

$$
I \%=\frac{\left(\mu_{c}-\mu_{e}\right)}{\mu_{c}} \times 100
$$

Where $I \%$ is the percentage of inhibition, $\mu_{c}$ and $\mu_{e}$ are average growth rates of negative controls and exposed S. subspicatus respectively. $I \%>0$ and $I \%<0$ were considered in this current work as inhibitory and stimulatory effects respectively.

Values of $\mathrm{EC}_{50}$ were calculated by selecting the most approximate non-linear regression models. One-sample $t$-test was carried out to verify the significance of algal growth rate changes, regardless of being inhibition or stimulation. One-way ANOVA and post-hoc Tukey's multiple comparison test were used to assess the existence of toxic first flush. All the statistical analysis was performed by GraphPad Prism (version 5.02 for Windows, San Diego, USA) assuming Gaussian distribution and variance homogeneity in a significance level of $\mathrm{P} \leq 0.05$.

\section{RESULTS AND DISCUSSION}

\subsection{EC 50 values}

EC50 values of the July 1 rain in different exposures and runoff elapsed times are presented in Table 1. It was not possible to calculate values of EC5096 (at the $96^{\text {th }}$ hour) due to low inhibitory effects within the entire range of stormwater concentrations. The concentrationresponse curves with considerable small slopes indicated that regardless the exposure to different stormwater concentrations; the measured effects were nearly constant after 96-h period.

\subsection{Rain event 1 - June 18, 2009}

The stormwater runoff discharged on June 18, in most cases, stimulated S. subspicatus growth (Figure 2). Stimulatory effects might be related to the presence of some compounds in the stormwater. It has been reported that a number of trace metals are used by living organisms to stabilize protein structures, to catalyze enzymatic reactions and to facilitate electron transfer reactions in the photosynthetic and respiratory processes $[15,16]$. Harmless effects towards 
Daphnia sp. reproduction from log-yards runoff in contact with two different wood species (Picea abies and Pinus sylvestris) have been reported [6].

According to the statistical tests (one-way ANOVA and post-hoc Tukey's multiple comparison test), considerable intra-storm variation and significant differences $(p<0.05)$ of the effects on S. subspicatus were observed after the first $48 \mathrm{~h}$ of exposure. Runoff samples collected on the last stages of the runoff - the last 110 minutes - posed significant higher stimulatory effects (Tukey's test; $\mathrm{p}<0.05$ ) after 72 and $96 \mathrm{~h}$ exposure in comparison to the runoff samples collected throughout the first 100 minutes (Figure 2c1-c2; 2d1-d2).

Different exposure concentrations (\% v:v) caused variable effects towards S. subspicatus and reasonably the lower the stormwater concentration $(\% \mathrm{v}: \mathrm{v})$ : the lower the observed stimulation or inhibitory effects (Figure 2a-d).

\subsection{Rain event 2 - July 1, 2009}

As shown in Figure 3, stormwater runoff of July 1 posed in most cases high inhibitory effects (one-sample $t$-test; $\mathrm{p}<0.05$ ) to $S$. subspicatus growth reaching up to $100 \%$ in some cases (Figure 3a1). However, the inhibitory effects decreased progressively with the exposure time, and a considerable reduction in the effects was observed when comparing exposures of $24 \mathrm{~h}$ and $96 \mathrm{~h}$. This might be related to an inherent process of the test organisms to detoxify and overcome the initial hazardous environment suggesting that time of exposure played an important role over the effects towards algae growth (Figure 3b-d). It was observed that the period required to overcome toxic effects was positively related to the stormwater concentrations.

In some cases it was observed a shift from inhibition to growth stimulation in which can be explained by the possible transformation and/or degradation (by e.g. light, bacteria) of certain compounds that were causing toxic effects in the first days

Table 1: EC50 values with 95\% confidence intervals calculated for exposures of 24, 48, 72 and $96 \mathrm{~h}$. Stormwater runoff event July 1. Values given in \% v:v [14]

\begin{tabular}{|c|c|c|c|c|c|c|c|c|}
\hline $\begin{array}{c}\text { Runoff } \\
\text { Elapsed } \\
\text { time (min) }\end{array}$ & $\mathrm{EC} 50_{24}$ & $95 \% \mathrm{CI}$ & $\begin{array}{c}\mathrm{EC} 50_{4} \\
8\end{array}$ & $95 \% \mathrm{CI}$ & $\mathrm{EC} 50_{72}$ & $95 \% \mathrm{CI}$ & $\begin{array}{c}\mathrm{EC}^{5} 0_{9} \\
6\end{array}$ & $95 \% \mathrm{CI}$ \\
\hline 15 & 9.5 & $7.3-12.2$ & 19.3 & $11.4-32.6$ & 45.9 & $17.8-118.7$ & ND & $\mathrm{ND}$ \\
\hline 40 & 10.0 & $7.5-13.5$ & 31.0 & $11.3-84.9$ & 60.6 & $12.6-292.4$ & ND & ND \\
\hline 65 & 13.2 & $9.6-18.5$ & 23.5 & $6.8-81.0$ & 69.2 & $7.0-671.0$ & ND & ND \\
\hline 90 & 11.9 & $4.6-31.0$ & 32.5 & $9.8-108.0$ & $176.1^{\mathrm{a}}$ & $\mathrm{ND}^{\mathrm{a}}$ & ND & ND \\
\hline 115 & 21.2 & $13.0-34.4$ & 106.8 & ND & ND & $\mathrm{ND}$ & ND & ND \\
\hline
\end{tabular}

ND-Not determined due to low inhibitory effects; ${ }^{a}$ imprecise theoretical model 


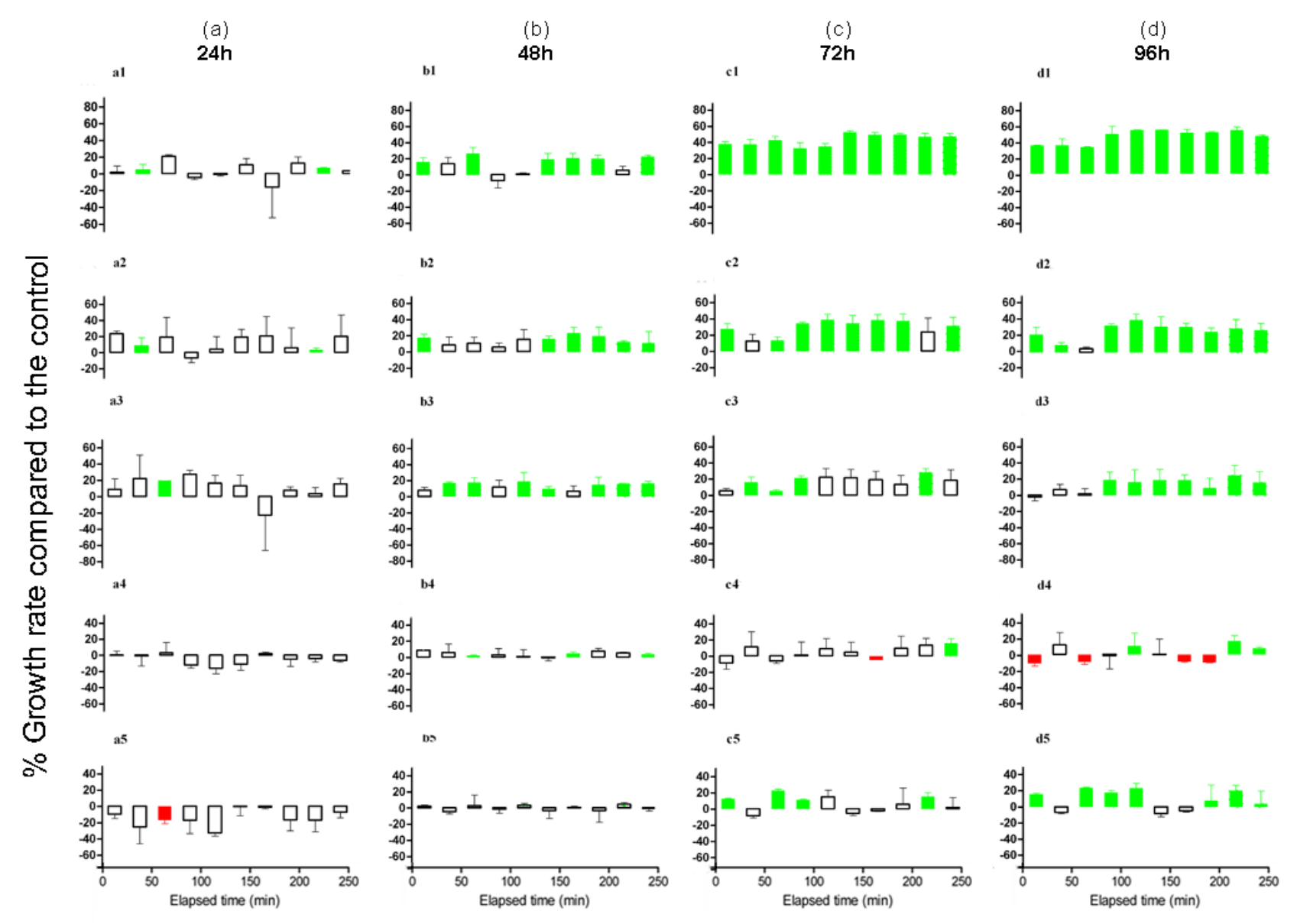

Figure 2: S. subspicatus growth rate \% in comparison to the control throughout the rain event of June 18 in exposures of (a) $24 h$; (b) 48 ; (c) $72 \mathrm{~h}$ and; (d) 96h. Each row represents stormwater concentrations of (1) 50; (2) 12.5; (3) 3.13; (4) 0.79 and; (5) $0.2 \%$ (v:v). Whiskers Standard deviation. White bars - not significant (one-sample t-test, $p>0.05$. [14] 


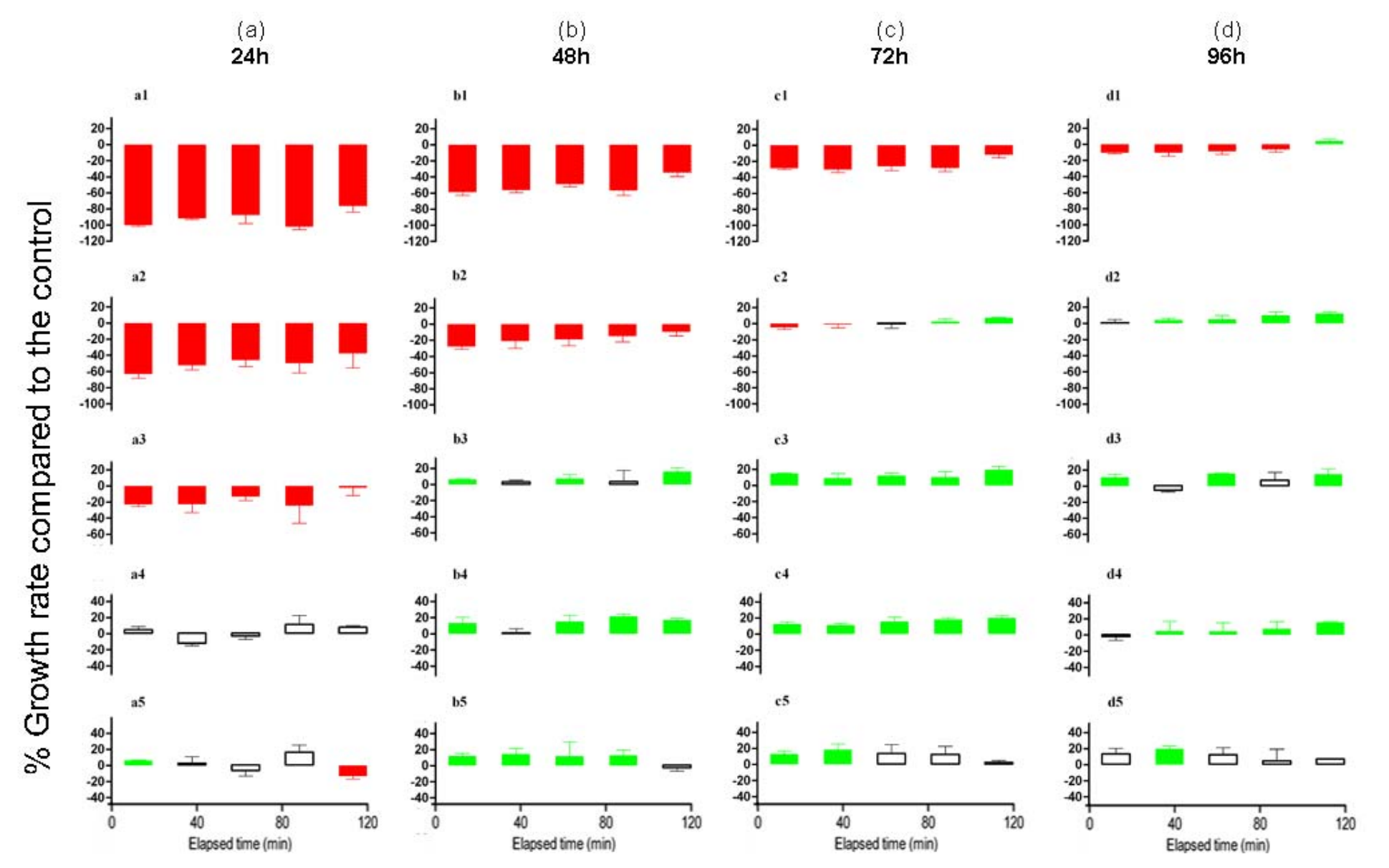

Figure 3: S. subspicatus growth rate \% in comparison to the control throughout the rain event of July 1 in exposures of (a) $24 h$; (b) 48 ; (c) $72 h$ and; (d) 96h. Each row represents different stormwater concentrations of (i) 50; (ii) 12.5; (iii) 3.13; (iv) 0.79 and; (v) $0.2 \%$ (v:v). Whiskers Standard deviation. White bars - not significant (one-sample t-test, $p>0.05$ ). [14] 


\subsection{Toxic first flush effects: normalized toxicity vs normalized runoff volume}

To remove the effects of runoff flow rates on the interpretation of toxicity results, an evaluation on the basis of intra-storm normalized toxicity proportion is recommended [8]. In the current study, the normalized toxicity is expressed in terms of acute toxic units $\left(\mathrm{TU}_{50}=100 / \mathrm{EC} 50\right)$.

The occurrence of toxic first flush was evident by taking into account 24; 48 and 72-h exposures, once a greater normalized toxicity proportion in the earlier stages of the runoff event in comparison to the normalized discharged volume were observed (see Figure 4). It can be observed that 42,51 and $50 \%$ of the toxic effects during exposures of 24,48 and $72 \mathrm{~h}$ respectively were associated with the first $4 \%$ of the total discharged volume and $13 \%$ of the total storm duration (Figure 4 ).

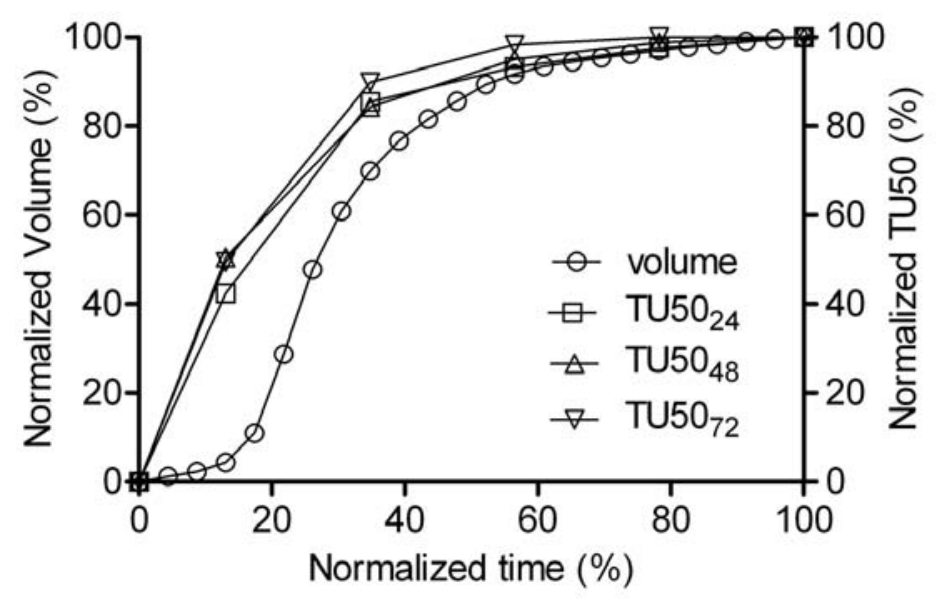

Figure 4: Discharged volumes and toxic units (TU50) as a function of storm elapsed time on a normalized basis for acute exposures of 24, 48 and $72 h$. [14]

\subsection{Rain events characteristics}

The differences observed in the magnitude and nature of $S$. subspicatus responses from growth stimulation to inhibition - when comparing both rain events, might have been influenced by the hydrological factors (rain intensity, precipitation heights, antecedent dry period and duration) and the stormwater runoff physico-chemical characteristics. Possible relationships between $S$. subspicatus responses, storm characteristics and chemical pollutant concentrations were evaluated based on the hydrographs and pollutographs (COD, $\mathrm{pH}$ and conductivity).

Significant differences $(t$-test, $\mathrm{p}<0.05)$ observed between metals concentrations, $\mathrm{pH}$ and conductivity of the two runoff events, might explain the opposite responses of the test organisms. The results showed also that the $\mathrm{pH}$ of the runoff from July 1 was significantly lower $(\mathrm{p}<0.05)$ suggesting that to some extent, low $\mathrm{pH}$ might have been responsible to the observed $S$. subspicatus growth inhibition Increased toxicity with 
lower $\mathrm{pH}^{\prime}$ s might be related to an increase of metals solubility and bioavailability of prevailing free metal ions [17].

Differences in metal concentrations were also observed and the concentrations of $\mathrm{Cr}$, $\mathrm{Ni}, \mathrm{V}, \mathrm{Ba}$, and $\mathrm{Zn}$ were significantly higher $(t$-test; $\mathrm{p}<0.05)$ in the rain event of July 1 , with the exception of $\mathrm{Cu}(\mathrm{p}<0.05)$. The toxic effects due to metal contents in woodrelated areas are reported in the literature by [5,6]. Furthermore, according to [18] metabolic processes such as photosynthesis have been shown to be very sensitive to the presence of toxic metals.

Other aspects that could have contributed to the responses from $S$. subspicatus are the hydrological factors involved in the rainfall-runoff process such as storm duration, precipitation heights and average rainfall intensity. Whereas $3 \mathrm{~mm}$ of precipitation was recorded during 115 minutes in June 18 (average intensity of $1.56 \mathrm{~mm} / \mathrm{h}$ ), only $1.25 \mathrm{~mm}$ was recorded during 45 minutes in July 1 (average intensity of $1.66 \mathrm{~mm} / \mathrm{h}$ ). Lower amounts of stormwater, but a nearly similar rainfall average intensity during the event of July 1 might be the cause of higher concentrations of metals and $\mathrm{H}^{+}$detected within the runoff water. Assuming that similar rainfall intensities as observed, are able to wash-off the log-yard the same mass of contaminants; higher concentrations will be detected in lower amounts of water, posing then higher toxic effects.

Similar results concerning the roles played by hydrological aspects over the toxic effects of runoff have been reported by [2]. The authors also observed that at the same rain intensities, rainfall duration and degrees of toxic effects were inversely related.

\section{CONCLUSIONS}

The runoff originated from two different rain events over the same log-yard area posed different effects on the freshwater, green microalgae $S$. subspicatus. Whereas the runoff of the first rain event had no negative effects to $S$. subspicatus posing in most cases stimulatory effects, the runoff from the second rain event inhibited algae growth. The differences in runoff physico-chemical characteristics combined with the hydrological factors (precipitation and duration) of each rain event explained the opposite effects on S. subspicatus observed during the current investigation.

Despite the lack of negative effects to $S$. subspicatus growth, stimulatory effects posed by the first runoff event indicate that the necessity of treating these waters before discharging into natural recipients can not be ruled out since the stormwater runoff might contribute to environmental impacts such as algae blooming and eutrophication.

The intra-storm magnitude and variability of the inhibitory effects posed by the $2^{\text {nd }}$ runoff event confirmed the hypothesis of toxic first flush phenomenon. The evaluation on a normalized basis showed that 42,51 and $50 \%$ of the inhibitory effects during exposures of 24,48 and $72 \mathrm{~h}$ are associated with the initial $4 \%$ of the total discharged volume and $13 \%$ of the storm duration.

To conclude, the current investigation brings a better understanding of a subject that has not been widely explored: the intra-storm magnitude and variability of the potential environmental effects posed by log-yards runoff. Toxicity studies can provide useful information for an appropriate design and implementation of stormwater runoff management strategies. The fact that negative effects were observed in the two runoff events analyzed in this study, raises concern about the potential environmental threats posed by runoff originated from wood-based industrial areas during the entire hydrological year. 


\section{ACKNOWLEDGEMENTS}

The PhD scholarship given by CAPES Foundation-Brazil Ministry of Education to the first author, the financial support to the research project from the Swedish Knowledge Foundation (KK-Stiftelsen) and the Linnaeus University (Faculty of Natural Sciences) are acknowledged. Finally the authors are thankful to Birte Rancka and Christina Esplund for their valuable help in the laboratory during the execution of the experiments.

\section{REFERENCES}

[1] E. Eriksson, A. Baun, L. Scholes, A. Ledin, S. Ahlman, M. Revitt, C. Noutsopoulos, P.S. Mikkelsen, Selected Stormwater priority pollutants - A European perspective, Sci. Total Environ. 383 (2007), 41-51.

[2] D. Greenstein, L. Tiefenthaler and S. Bay, Toxicity of parking lot runoff after application of simulated rainfall, Arch. Environ. Contam. Toxicol. 47(2004), 1992006.

[3] R.T. Rozenkrantz, C.A. Pollino, D. Nugegoda, and A. Baun, Toxicity of water and sediment from stormwater retarding basins to Hydra hexactinella, Environ. Pollut. 156(2008), 922-927.

[4] G. Libralato, C. Losso and A. Volpi Ghirardini, Toxicity of untreated wood leachates towards two saltwater organisms (Crassostrea gigas and Artemia franciscana), J. Hazard. Mater. 144(2007), 590-593.

[5] H.C. Bailey, J.R. Elphick, A.Potter, E. Chao, D. Konasewich and J.B. Zak, Causes of toxicity in stormwater runoff from sawmills, Environ. Toxicol. Chem. 18(1999), 1485-1491.

[6] H.C. Bailey, J.R. Elphick, A. Potter and B. Zak, Zinc toxicity in stormwater runoff from sawmills in British Columbia, Water Res. 11 (1999), 2721-2725.

[7] A. Hedmark and M. Sholz, Review of environmental effects and treatment of runoff from storage and handling of wood, Bioresour. Technol. 99(2008), 59976009.

[8] M. Kayhanian, C. Stansky, S. Bay, S.-L. Lau and M.K. Stenström, Toxicity of urban highway runoff with respect to storm duration, Sci. Total Environ. 389(2008), 386-406.

[9] V. Ribé, E. Nehrenheim. M. Odlare and S. Waara, Leaching of contaminants from untreated pine bark in a batch study: Chemical analysis and ecotoxicological evaluation, J. Hazard. Mater. 163 (2009), 1096-1100. 
[10] B.R. Taylor, J.S. Goudey, and N.B Carmichael, Toxicity of Aspen Wood Leachate to Aquatic Life: Laboratory studies, Environ. Toxicol. Chem. 15(1996), 150-159.

[11] B.R. Taylor, and N. B Carmichael, Toxicity and Chemistry of Aspen Wood Leachate to Aquatic Life: Field Study, Environ. Toxicol. Chem. 22 (2003), 20482056.

[12] T.P.T Pham, C. Cho, and Y. Yun, Environmental fate and toxicity of ionic liquid: A review, Water Res. 44(2010), 352-372

[13] Vinrot, E. 2008. Preliminary Studies on Stormwater from the Wood Industry Sector: AB Gustaf Kähr Industrial Site, Nybro, Sweden. Technical Report. Faculty of Natural Sciences and Technology, Linnaeus University, Kalmar- Sweden.

[14] F. Kaczala, P.S. Salomon, M. Marques, E. Granéli, W. Hogland, Effects from log-yard stormwater runoff on the microalgae Scenedesmus subspicatus: Intra-storm magnitude and variability, J. Hazard. Mater. In Press.

[15] M.A. Torres, M.P. Barros, S.C.G. Campos, E. Pinto, S. Rajamani, R.T. Syre and P. Colepicolo, Biochemical biomarkers in algae and marine pollution: A review, Ecotoxicol. Environ. Saf. 71(2008), 1-15.

[16] H.V. Perales-Vela, J.M. Pena-Castro, R.O. Canizares-Villanueva, Heavy Metal detoxificiation in Eukaryotic microalge, Chemosphere. 64 (2006), 1-10.

[17] H.A. Gamilla and F.A. Naglaa, Estimation of Hazard Concentration of Industrial Wastewaters using Algal Bioassay, Bull. Environ. Contam. Toxicol. 63(1999), 407-414.

[18] Silva, S.A. Figueiredo, M.G. Sales, C. Delerue-Matos, Ecotoxicity tests using the green algae Chlorella vulgaris - A usefool tool in hazardous effluents management, J. Hazard. Mater. 167(2009), 179-185. 